\title{
HEC-RAS Hidrodinamik Model Kullanılarak Kararlı Akım Analizi: Nevşehir, Türkiye Örneği
}

\author{
Kagan Cebe $^{1^{*}}$, Omer Bilhan ${ }^{2}$ \\ 1* Nevşehir Hacı Bektaş Veli Üniversitesi, Mühendislik ve Mimarlık Fakültesi, İnşaat Mühendisliği Bölümü, Nevsehir, Türkiye, (ORCID: 0000-0003-1288-1362), \\ kcebe@ nevsehir.edu.tr \\ 2 Nevşehir Hacı Bektaş Veli Üniversitesi, Mühendislik ve Mimarlık Fakültesi, İnşaat Mühendisliği Bölümü, Nevsehir, Türkiye, (ORCID: 0000-0002-8661-6097), \\ omerbilhan@nevsehir.edu.tr
}

(International Conference on Design, Research and Development (RDCONF) 2021 - 15-18 December 2021)

(DOI: $10.31590 /$ ejosat.1039311)

ATIF/REFERENCE: Cebe, K. \& Bilhan, O. (2021). HEC-RAS Hidrodinamik Model Kullanılarak Kararlı Akım Analizi: Nevşehir, Türkiye Örneği. Avrupa Bilim ve Teknoloji Dergisi, (32), 135-141.

Öz

Nevşehir Hacı Bektaş Veli Üniversitesi, Bilimsel Araştırma Projeleri Birimi tarafından desteklenen ve 2017 yılında tamamlanan "Saha Çalışmaları ve Nümerik Modeller Kullanılarak Kızılırmak Havzasında Sediment Taşııımı ve Birikiminin Analizi" başlıklı proje kapsamında Nevşehir ili sınırları içerisinde Kızılırmak nehri üzerinde yedi farklı ölçüm noktasında akarsu taban topoğrafyası ve akım ölçümleri gerçekleştirilmiştir. Proje alanı Kızılırmak nehri üzerinde Gülşehir ilçesinden Sarıhıdır köyüne kadar olan 32.472km'lik bir güzergahı kapsamaktadır. Bir boyutlu kararlı akım koşullarında su yüzü profil hesaplarını gerçekleştirmek amacıyla ABD Ordusu Mühendisler Birliği, Hidrolojik Mühendislik Merkezi (CEIWR-HEC) tarafindan geliştirilmiş olan Akarsu Analiz Sistemi (HEC-RAS v.6.0) yazılımı kullanılarak bir hidrodinamik model oluşturulmuştur. Sayısal yükseklik haritaları (SYM/DEM) kullanılarak HEC-RAS yazılımının Mapper alt bileşeni ile nehrin ana kanalına ait güzergah belirlenmiş, taban kotları ve düzensiz ana kanal kesitleri modele uygulanmıştır. Model, bir boyutlu kütle korunum ve momentum eşitliklerini kullanarak kararlı akım koşullarında su derinliklerini hesaplamaktadır. Modelde, enerji kayıpları Manning eşitliği, kesit değişimlerinde ise hız yüksekliği daralma/genişleme katsayıları ile çarpılarak hesaplanmaktadır. HEC-RAS modeli ile hesaplanan su derinlikleri, ölçüm sonuçları ile karşılaştırılmıştır.

Anahtar Kelimeler: SYM, Kızılırmak, HEC-RAS, Su yüzü profili.

\section{Steady Flow Analysis Using HEC-RAS Hydrodynamic Model: Case of Nevşehir Province, Turkey}

\begin{abstract}
The stream bottom topography and flow measurement data at seven different sampling point on the Kizilırmak River in the Nevsehir province are obtained within the scope of the project titled "Analysis of Sediment Transport and Accumulation in the Kizilirmak Basin using Field Studies and Numerical Models", completed in 2017 which was supported by the Nevsehir Haci Bektas Veli University Scientific Research Projects Unit. The project area compromises a $32.472 \mathrm{~km}$ long path with an irregular cross section, from Gülşehir, to Sarıhdır Village on Kızılırmak River. A hydrodynamic model was created by using US Army Corps of Engineers, Hydrologic Engineering Center's (CEIWR-HEC) River Analysis System (HEC-RAS v.6.0) in order to perform one-dimensional steady flow surface profile computations. The route, elevations and cross sections of irregular main channel was derived from digital elevation maps (DEM) accomplished in the HEC-RAS Mapper portion of the software. The model calculates water depths based on the solution of the one-dimensional energy equation. Energy losses were evaluated by Manning's equation and contraction/expansion coefficient multiplied by the change in velocity head. The water depths calculated with HEC-RAS model were compared with the field measurements.
\end{abstract}

Keywords: DEM, Kizilirmak, HEC-RAS, Water surface profile.

*Sorumlu Yazar: kcebe@nevsehir.edu.tr 


\section{Giriş}

Hidrodinamik modeller, hareket halindeki akışkanlar için sıcaklık, tuzluluk ve basınçtaki değişikliklere bağlı olarak hız bileşenlerini, akış hızlarını, yüzey seviyesi değişikliklerini, basınç gradyanlarını ve yoğunluk değişikliklerini tahmin etmek için araçlar sağlar. Hidrodinamik modeller, modellenmek istenen yüzey su kütlesinin yapısına göre bir boyutlu (1-D), iki boyutlu (2-D) ve üç boyutlu (3-D) modeller olmak üzere başlıca üç grupta değerlendirilebilir. Yüzeysel sularda suyun hareketini simüle etmek için birçok hidrodinamik model geliştirilmiştir. Bunlardan en s1k kullanılanları Storm Water Management Model (SWMM), Delft3D-FLOW, MIKE ve Hydrologic Engineering Center-River Analysis System (HEC-RAS) olarak sayılabilir. Türkiye'ye özgü hazırlanan hidrodinamik modeller ise HYDROTAM-3D ve HIDROTURK olarak siralanabilir.

SWMM, yağış ile oluşan yüzeysel akışların, birleşik kanalizasyon ve diğer drenaj sistemleri ile ilgili planlama, analiz ve tasarım için dünya çapında kullanılan bir modeldir. SWMM'nin bileşeni olan 1-B hidrodinamik model, Extended Transport Model (EXTRAN), yüzey sularının akışının simülasyonu için tüm dünyada yaygın olarak uygulanmaktadır (Rossman, 2006, 2017).

Delft3D-FLOW, doğrusal veya doğrusal olmayan sınırlara uygun bir 1zgara üzerindeki gelgit ve meteorolojik zorlamalardan kaynaklanan kararsız akımı ve taşıma olaylarını 2-D veya 3-D simule eden bir hidrodinamik ve taşıma simülasyon programıdır (Deltares, 2021).

MIKE 11 en yaygın kullanılan hidrodinamik modellerden biridir. Danimarka Hidrolik Enstitüsünde su yüzü profillerinin simülasyonu ve akarsu akımlarının simülasyonu için geliştirilmiştir. Model, kararsız akım denklemlerini çözmek için sonlu farklar yaklaşımını ve çift tarama algoritmasını kullanır. MIKE 11 modeli, düzensiz açık kanallar için tasarlanmıştır ve setler, bentler ve köprüler gibi akarsu üzerindeki yapıların etkileri ile birlikte akımı simüle etme yeteneğine sahiptir (DHI, 2017).

Kanal içerisindeki akımın analizinde ve taşkın yatağ simülasyonunda kullanılan en yaygın kullanılan modellerden biri ABD Ordusu Mühendisler Birliği tarafindan geliştirilen HECRAS, açık kanallarda ve taşkın yataklarında 1-D ve 2-D kararsız akışı simüle eden bir modeldir (Brunner \& CEIWR-HEC, 2021).

Üç boyutlu hidrodinamik, taşıma ve su kalitesi modeli (HYDROTAM-3D), Türkiye'de kıyı alanları için geliştirilmiş ilk ulusal 3 boyutlu hidrodinamik, taşıma ve su kalitesi modelidir (Balas \& Özhan, 2000; Cebe \& Balas, 2016). Türkiye'nin ilk ulusal hidrolojik, hidrodinamik, hidrojeolojik, su kalitesi ve ekolojik modeli olan HIDROTURK, su kaynaklarının sürdürülebilir yönetimi için geliştirilmiştir. HIDROTURK'un hidrodinamik model bileşeni ayrıca yüzey su kütlelerindeki hız bileşenlerini, akış hızlarını ve yüzey seviyesi değişikliklerini analiz etmeyi amaçlamaktadır. HIDROTURK, tekil veya entegre çalışabilen 1-D, 2-D ve 3-D hidrodinamik modelleri içerir (Balas \& Cebe, 2021).

1775 yılında ilk temelleri atılan ve 1802 yılında kalıcı olarak kurulan, ABD Ordusu Mühendisler Birliği (US Army Corps of Engineers) tarafindan geliştirilen HEC-RAS (Hydrologic Engineering Centers River Analysis System), modelleme yazılım programı yardımıyla, grafik tabanlı olarak, akarsuları ya da açık kanallardaki akımların bir boyutlu analizleri gerçekleştirilebilmektedir. Hidrolik bilimi alanında çalışan araştırmacılar, HEC-RAS yazılımı kullanarak, son yıllarda, değişken ya da düzenli akımlar için su yüzü profili oluşturma, su kalitesi ve sediment taşınımı analizleri yapabilmektedir.

Araştırmacılar, HEC-RAS yazılımında, analiz için gereken arazinin topoğrafik ve morfolojik verilerine, uydu ve hava fotoğrafları kullanılarak ulaşılabilmektedir. Ayrıca, Topoğrafyanın sayısal gösterimi açısından, Sayısal Yükseklik Modeli SYM, (Digital Elevation Model-DEM), günümüzde, SRTM, ASTER, LANDSAT gibi uydu gözlem verileri ile üretilebilmektedir.

Literatürde tamamlanan çalışmalar değerlendirilirse, HECRAS modeli kullanılarak yapılan çalışmaların büyük çoğunluğu taşkın analizi konusunda bir bölümünün ise su yüzü profillerinin simülasyonu amacıyla gerçekleştirildiği görülmektedir. $\mathrm{Bu}$ çalışmalar kapsamında genellikle, akarsularda taşkın analizi HEC-RAS paket programını kullanarak taşkın için yayılım haritaları oluşturmuş ve yerlelşim merkezlerinin olası bir taşkından nasıl etkileneceği belirlenmeye çalışılmıştır. Tektaş ve Polat (2021), Diyarbakır ili Çınar ilçe Merkezi'nde dere yatağ için mevcut harita ve röleveleri kullanarak, HEC-RAS yazılımı yardımıyla, Çakmak Deresi'nde 1 boyutlu ve 2 boyutlu hidrolik hibrit model oluşturmuşlardır. Yılmaz v.d. (2020) Eskişehir ili sınırlarında içerisinde yapılmış bir köprünün 50 yıllık ve 100 yıllık taşkın debilerini esas alarak, güvenilirliğini ArcGIS ve HEC-GeoRAS ve HEC-RAS ile analiz etmişlerdir. Doğu ve Yıldız (2019) Kızılırmak nehri, Çoruhözü deresinin Kırıkkale ilinden geçen ve Devlet Su İşleri Genel Müdürlüğü tarafından ıslah çalışması gerçekleştirilen 8 km'lik taşkın kanalını incelemişler ve bu kanalın 500 ve 100 yıllık taşkın debilerindeki güvenilirliğini HEC-RAS yazılımı ile analiz etmişlerdir. Maharjan ve Shakya (2016) Nepal'de tamamladıkları çalışmalarında, HEC-RAS ve diğer yazılımları kullanarak tek boyutlu ve iki boyutlu yüzey akış analizi gerçekleştirmişlerdir. Wang (2014), çalışmasında, gerçek bir proje üzerinde HECRAS modeli kullanarak su yüzeyi profil analizi gerçekleştirmiştir.

\section{Materyal ve Metot}

\subsection{Saha Çalışmaları}

Türkiye'nin en önemli ve yenilenemeyen doğal kaynaklarından biri olan su kaynaklarını tespit etmek, geliştirmek ve kullanmak maksadıyla ülkemiz 26 büyük drenaj havzasına ayrılmıştır. Kızılırmak Havzasının orta Kızılırmak bölümünde yer alan Kızılırmak nehri, Türkiye topraklarından doğarak yine Türkiye topraklarından denize dökülen ülkemizin en uzun (yaklaşık $1355 \mathrm{~km}$ ) akarsuyudur. Adını suyunun renginden alan, antikçağda ise tuzlu akarsu anlamına gelen Halys adıyla anılan Kızılırmak, Anadolu'da kurulmuş medeniyetlere hep ev sahipliği yapmıştır. Nehir adını akarsu yatağının tabanında yer alan, üçüncü zaman ortalarında çökelmiş kırmızı renkli kumlu killi tortudan almaktadır (Önal, 2009).

1962 ve 1973 yılları arasında Kızılırmak üzerinde, Bafra Çetinkaya köprüsünden alınan sediment örneklerinden elde edilen analiz raporlarına göre, Kızılırmak Nehri'nin ortalama olarak \% 26 kum, \% 74 kil ve silt taşıdığı, deltanın kuzeyinde bulunan ince kum, kum, silt ve siltli kum ardalanmalarından oluşan tipik delta ve deniz kıyısı çökellerinin Kuaternere ait 
olduğu ve burada zeminden alınan örneklerin \% 20-72 silt ve \% 28-80 kum ihtiva ettiği belirlenmiştir (Yılmaz, 2005). Saha çalışmalarının gerçekleştirildiği bölgeye ait jeoloji haritası Şekil 1 'de sunulmuştur.

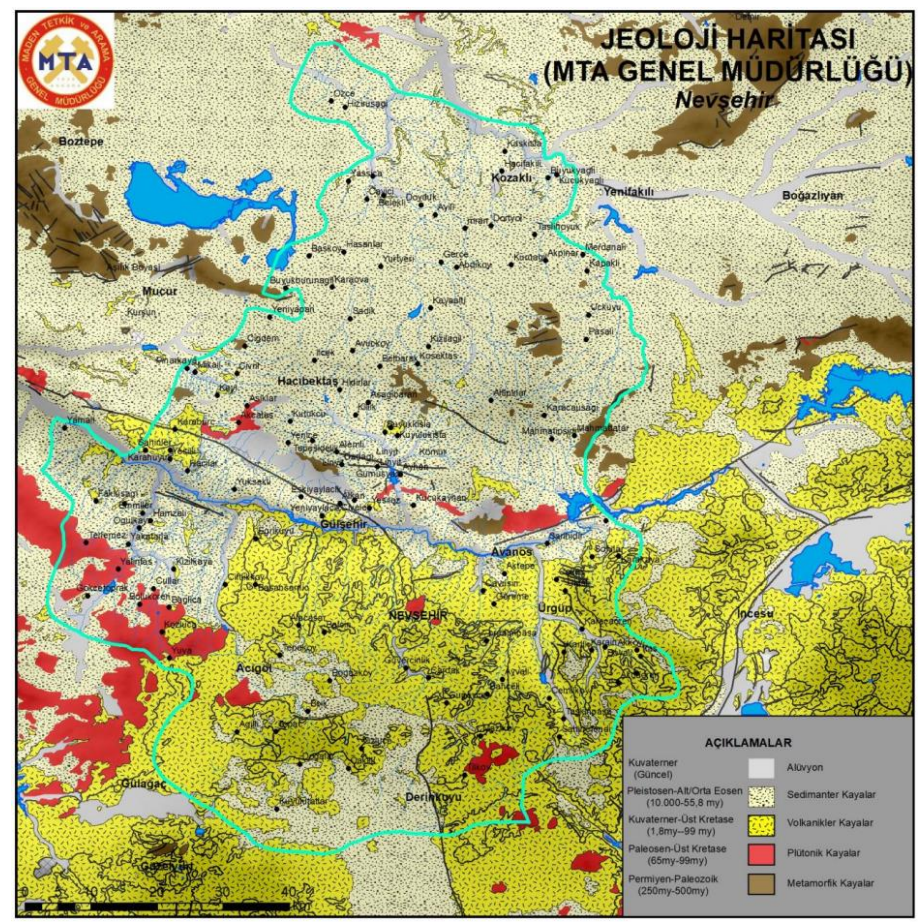

Şekil 1. Nevşehir İli Jeoloji Haritası (Acarlar v.d., 2002)

$\mathrm{Bu}$ çalışma kapsamında kullanılan verilere ait saha çalışmaları Orta Kızılırmak Havzasında yer alan Nevşehir İli sınırları içerisinde tamamlanmıştır. Orta Anadolu'da yer alan Nevşehir ili, yaklaşık $38-39^{\circ}$ Kuzey enlemi ve $34-35^{\circ}$ Doğu boylamı arasındadır. Konum olarak, Türkiye'nin neredeyse tam ortasında yer alır. Kentin Alanı yaklaşık 5467 km2'dir. Orta Anadolu'da yaygın bir toprak türü olan kahverengi topraklar Nevşehir de geniş bir yelpazeyi kaplamaktadır. (Bilhan, 2017).

Nehir, Sivas ili sınırlarında, Kızıldağ'ın güney yamaçlarından doğar, Kayseri, Nevşehir, Kırşehir, Kırıkkale, Ankara, Çankırı, Çorum ve Samsun illerinden geçerek Bafra Burnu'ndan denize dökülür. Kızılırmak Nehri'ne bağlanan başlıca iki ana kol bulunmaktadır. Uzunluğu 308km olan Delice Irmağı'nın yaklaşık $42 \mathrm{~km}$ uzunluğundaki bir bölümü Delice ilçesinin sınırlarından geçmektedir. Yamaç yüksekliği 650-750m arasında değişmekte olup, vadi derinliği Didiri (Sungurlu) köyü civarında 100m'dir. Kızılırmak'1n en büyük kollarından biri olan Gökırmak ise Batı-Doğu doğrultusunda uzanmaktadır. Kastamonu ili sınırları içerisinde Ilgaz Dağının Kuzey yamaçlarından kaynağını alır. Kızılırmak Nehri ağırlıklı olarak yağmur ve kar sularıyla beslenir ve rejimi düzensizdir. Kiz1lırmak Nehri ortalama debisi 184m³/s'dir (Önal, 2009).

Kızılırmak Nehri'nde yüksek kapasiteli barajların varlığı ve işletilmesi, bölgenin nüfus yoğunluğu Türkiye nüfus yoğunluk ortalamasının üzerinde olduğundan, doğal yapıda bozulmalar görülmektedir (Bilhan, 2017). Özellikle son y1llarda yaz aylarında, Nevşehir'in Avanos ilçesinden geçen Kızılırmak'ın kollarından biri olan Sarıhıdır Köyü mevkiindeki ırmak suları aşırı sıcaklardan dolayı zaman zaman kuruma tehlikesi ile karşı karşıya kalmaktadır. Saha çalışmalarının yürütüldüğü ölçüm noktaları ve koordinatları Şekil 2'deki harita üzerinde sunulmuştur.

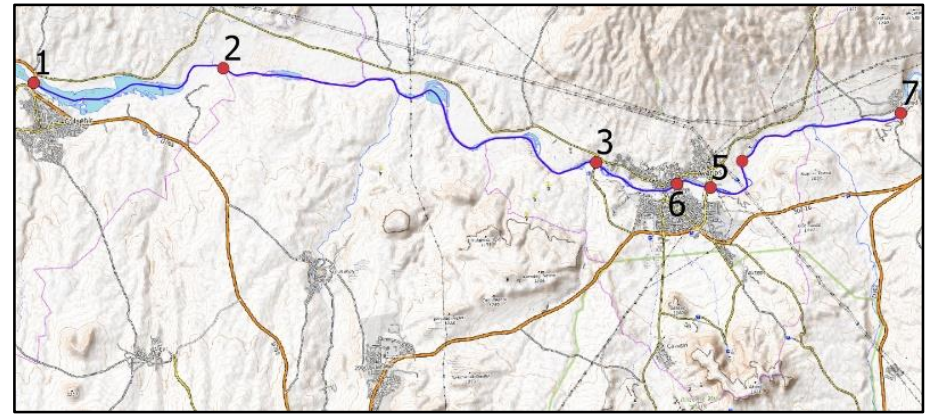

Şekil 2. Kızılırmak Nehri (Gülşehir-Sarıhıdır hattı) üzerinde saha çalışmalarının gerçekleştirildiği ölçüm noktaları

Saha çalışmaları kapsamında, Kızılırmak Nehri üzerinde belirlenen yedi örnekleme noktasında, debi ölçümleri ve nehrin taban topoğrafyasının çıkarılması amacıyla RiverRay ADCP Stream Pro ADCP cihazı (Şekil 3.) kullanılmıştır. Ayrıca cihaz üzerinde yer alan GPS yardımıyla koordinat tespitleri tamamlanmıştır.

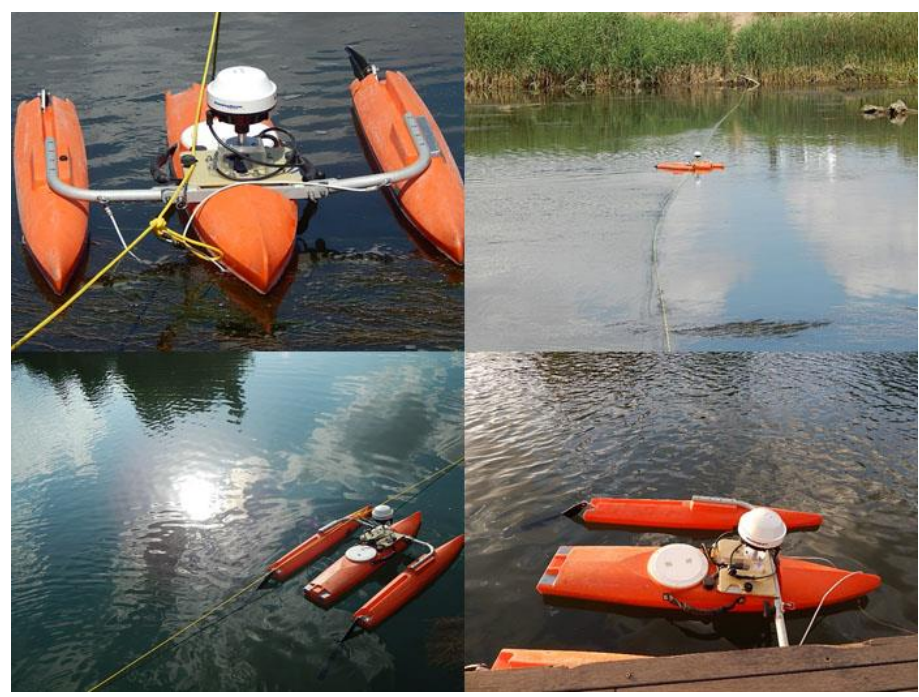

Şekil 3. Saha Çalışmalarında Kullanılan Riverray ADCP Çok Yönlü Debi Ölçüm Cihazı (Bilhan, 2017)

Saha ölçümleri sonucunda, ölçüm noktalarında akarsu kesit geometrisi ve taban kotları dışında, kesitlerde ortalama hız, maksimum hız, ortalama derinlik, maksimum derinlik ve debi de ölçülmüştür. Kesitlerde ölçülen hız dağılımları Şekil 4'de verilmektedir ve ölçülen veriler Tablo 1'de özetlenmektedir.

\subsection{HEC-RAS Hesap Yöntemi}

HEC-RAS ile tedrici değişen kararlı ve kararsız akımlarda su yüzü profili değişimleri ile menfezler, köprüler, şev üstündeki yapılar ve bentler gibi çok çeşitli engellerin akıma etkilerini göz önüne alarak su yüzü profillerini simüle etmek mümkündür (Brunner \& CEIWR-HEC, 2021).

Bir boyutlu, kararlı akımlar için su yüzü profillerini elde etmek için enerji denklemi (Eş. 1) standart adım yöntemi ile yinelemeli bir şekilde çözülerek bir kesitten diğerine hesaplanır (Brunner, 2021):

$$
Z_{2}+Y_{2}+\frac{a_{2} V_{2}^{2}}{2 g}=Z_{1}+Y_{1}+\frac{a_{1} V_{1}^{2}}{2 g}+h_{e}
$$

Burada $Z_{1}$ ve $Z_{2}$ kanalın taban kotları, $Y_{1} v Y_{2}$, kesitlerdeki su derinlikleri, $V_{1}$ ve $V_{2}$ ortalama akım hızları, $a_{1}$ ve $a_{2}$ h1z ağırlık katsayıları, g yerçekimi ivmesi ve $h_{e}$ enerji kaybıdır. 
Avrupa Bilim ve Teknoloji Dergisi

Tablo 1. Ölçüm Noktalarından Elde Edilen Veriler (Bilhan, 2017)

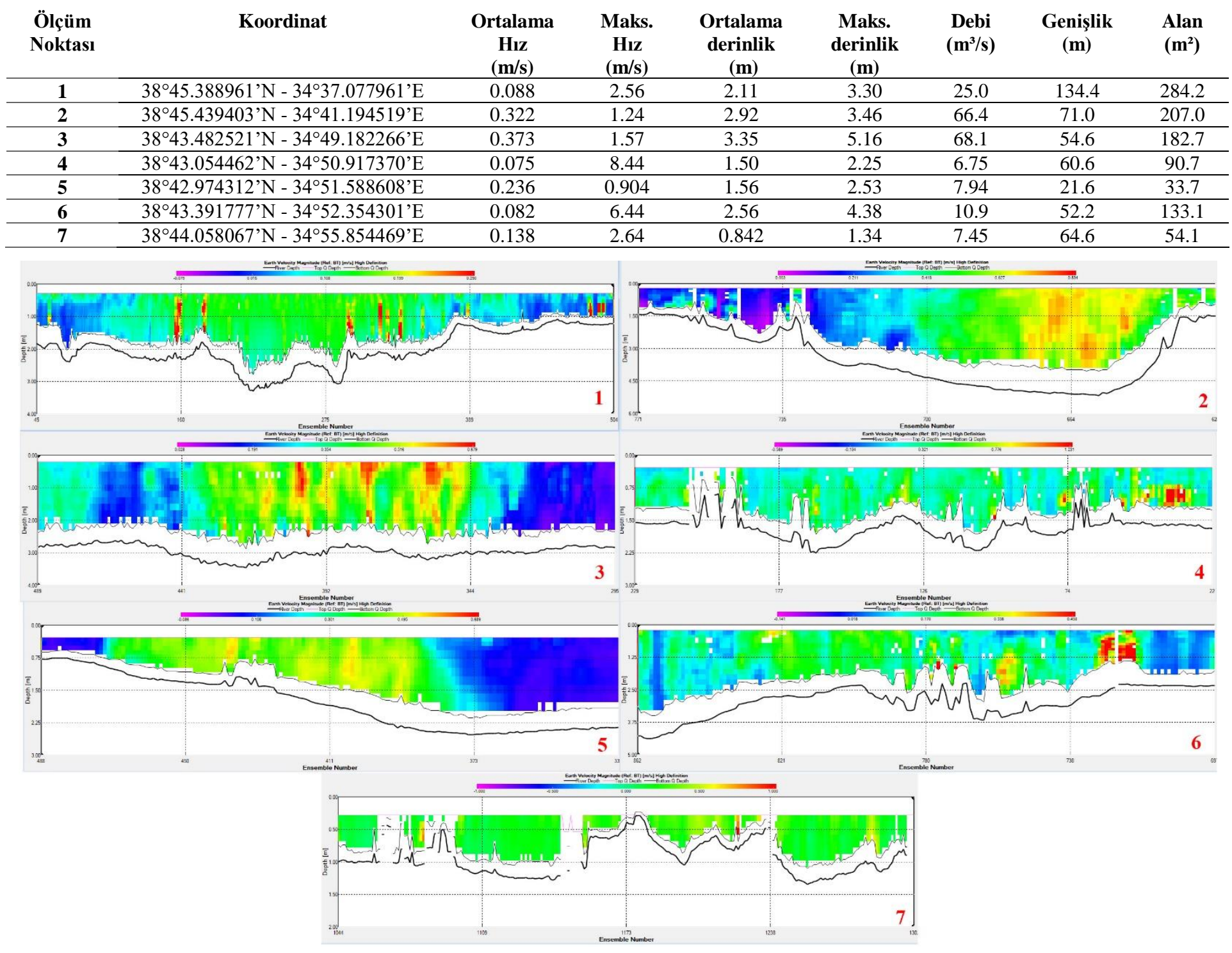

Şekil 4. Ölçüm Noktalarındaki Hız Dağıllmları (Bilhan, 2017)

Enerji denkleminde bulunan enerji kayıları kanaldaki daralma ve genişleme de göz önüne alınarak Eşitlik 2 ile hesaplanır (Brunner, 2021):

$h_{e}=L \bar{S}_{f}+C\left|\frac{a_{2} V_{2}^{2}}{2 g}-\frac{a_{1} V_{1}^{2}}{2 g}\right|$

Eşitlikte, $\mathrm{S}_{\mathrm{f}}$, iki kesit arasındaki sürtünme enerji kaybı eğimi, $L$ debi ağırlıklı hesaplanan kanal uzunluğu ve $C$ daralma, genişleme kayıp katsayısıdır. HEC-RAS farklı pürüzlülük değerlerine sahip olan bir kesit için toplam debiyi Manning denklemi ile hesaplamaktadır:

$Q=K S_{f}^{1 / 2}$

$K=\frac{1}{n} A R^{2 / 3}$

Burada $\mathrm{R}$ hidrolik yarıçap ve $\mathrm{n}$ Manning pürüzlülük katsayısını ifade etmektedir. Farklı pürüzlülük katsayılarına sahip taşkın yatağına sahip bir kesitteki (Şekil 5.) toplam debi ise kesitin farklı pürüzlülük değeri taşıyan bölümlerindeki $\mathrm{K}$ e-ISSN : 2148-2683 değerlerinin toplamı ile hesaplanmaktadır. Manning formülündeki (Eşitlik 3 ve 4) n pürüzlülük katsayısı ise aşağıdaki denklem ile hesaplanır (Brunner, 2021):

$n_{c}=\left[\frac{\sum_{i=1}^{N}\left(P_{i} n_{i}^{1.5}\right)}{P}\right]^{2 / 3}$

Burada $P_{i}$ i kesitine ait sslak çevre, $n_{i}$ i kesitine ait Manning pürüzlülüğü ve $\mathrm{P}$ değeri kanalın toplam sslak çevresini ifade etmektedir

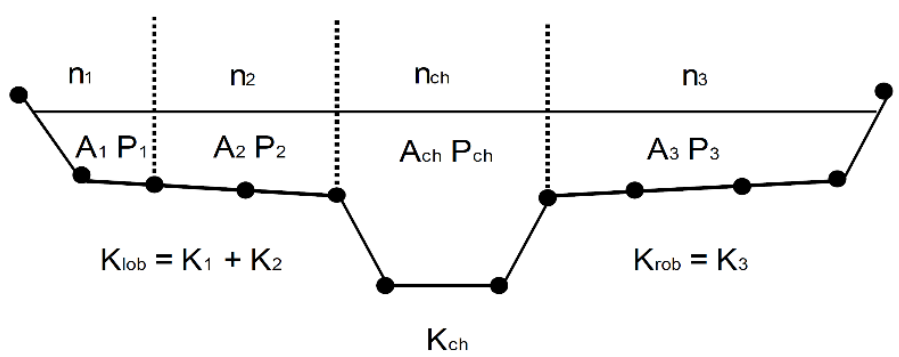

Şekil 5. HEC-RAS Bileşik Kesitli Kanalda Debi Hesaplama Yöntemi (Brunner, 2021) 
Akımın nehir rejinde olması halinde memba su yüzü için, sel rejiminde olması halinde mansap su yüzü için başlangıç su derinliği belirleyerek, toplam kayba göre yinelemeli bir metotla su derinliği hesaplanır (Brunner, 2021).

\subsection{Sayısal Verilerin İşlenmesi}

HEC-RAS, kanal geometrisinin ve su akımının hidrolik analizi için bir dizi veri kullanır. Bu veriler, akış boyunca bir dizi enine kesit oluşturmak için kullanılır. Akarsu boyunca tüm kesitler, sol başlangıç noktasından uzaklık ve yüksekliği içeren veri dizileri ile tanımlanır. Her bir kesitte, akarsu şevlerinin yerleri belirlenir ve bu yerler, kanal kesitinin sol taşkın yatağı, ana kanal ve sağ taşkın yatağı olarak üç farklı bölüme ayrılmak için kullanılır. Kanal geometrisini tanımlayan bu veriler ile birlikte kesite ve taşkın yataklarına ait Manning katsayıları, kanal daralma, genişleme katsayıları ve kanal üzerinde bulunan köprü, menfez, savak gibi hidrolik yapıların geometrik bilgilerinin modele girilmesi gerekir.

ArcGIS, QGIS gibi coğrafi bilgi sistemi tabanlı yazlımlar HEC-RAS ile birlikte sıkça kullanılmaktadır. Bu tür yazılımlar, HEC-RAS'ın temel girdileri olan akarsu güzergahı, kanal ve taşkın yatağı geometrisi ve kanal direnç katsayısı gibi uzamsal verilerle çalışmak için bir dizi araç ile bu verileri işlemek için yardımcı program ve prosedürleri içerir.

Çalışma kapsamında HEC-RAS modelini oluşturmak için Kızılırmak nehrinin Nevşehir ili sınırlarında kalan kısmına ait sayısal arazi modeli, NASA Shuttle Radar Topography Mission Global 1 (SRTM-G1) veri kaynakları kullanılarak oluşturulmuştur. Yaklaşık 30m çözünürlüğü olan SRTM-G1 yükseklik haritası ile (NASA JPL, 2013) elde edilen sayısal yükseklik modeli (SYM), ArcMap v10.2 (ESRI, 2011) yazılımı kullanılarak vektör bazlı bir sayısal yüzey modeli olan gelişigüzel dağılmış üçgen ağ (Triangular irregular networks,
TIN) modeline dönüştürülmüștür. CBS yazılımı üzerine kurulan HEC-GeoRAS (Cameron \& Ackerman, 2012) eklentisi ile TIN modeli üzerinde akarsu ana kanal ve taşkın yataklarının sınırları CBS haritası üzerinde çizilerek, HEC-RAS modelinde kullanılacak veri setleri haline dönüştülmüştür. HEC-GeoRAS ile hazırlanan TIN modeli ve akarsu ana kanal ve taşkın yataklarının (şev üstü) sınırları Şekil 6'da gösterilmektedir.

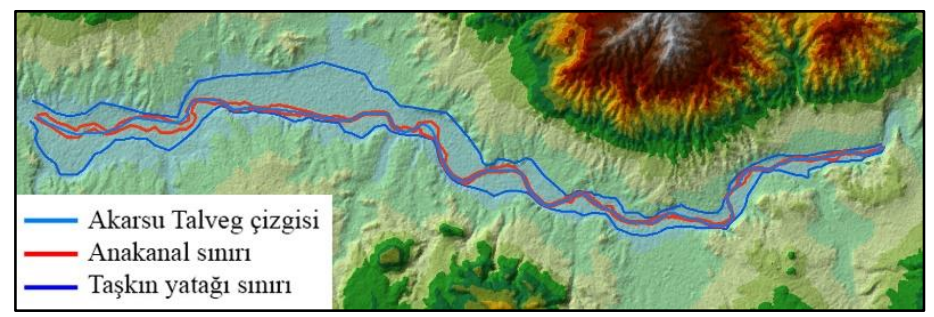

Şekil 6. ArcMap ve HEC-GeoRAS ile Hazırlanan TIN Modeli, Anakanal ve Taşkın Yatakları Sinırları

HEC-GeoRAS ile oluşturulan TIN modeli, anakanal, taşkın yatağı sınırları HEC-RAS modelinde kullanılmak üzere, yazılım içerisinde sayısal haritaları işlemek için kullanılan RAS Mapper birimine aktarılmıştır. RAS Mapper ile TIN yüzey modeli kullanılarak akarsu üzerinde aralarındaki mesafe 3500m'yi geçmeyecek şekilde ve akarsuyun fazla değişmeyen kesit özellikleri gösteren bölgelerinde anakanal ve taşkın yatağını temsil edecek enkesitler alınmıştır. Aktarılan TIN yüzey modeli, anakanal çizgisi, taşkın yatağı sınırları ve enkesit alınan bölgeler Şekil 7'de gösterilmektedir.

RAS Mapper modelinde oluşturulan enkesitlere ilave olarak saha çalışmalarında Riverray ADCP cihazı ile ölçüm noktalarında kaydedilen taban topoğrafyaları lineer enkesitlere dönüştürülerek anakanal üzerindeki ilgili noktalara tanımlanmıștır. Elde edilen bu enkesitler HEC-RAS modelinde akarsu kanal geometrisini temsil edecek şekilde kullanılmıştır.

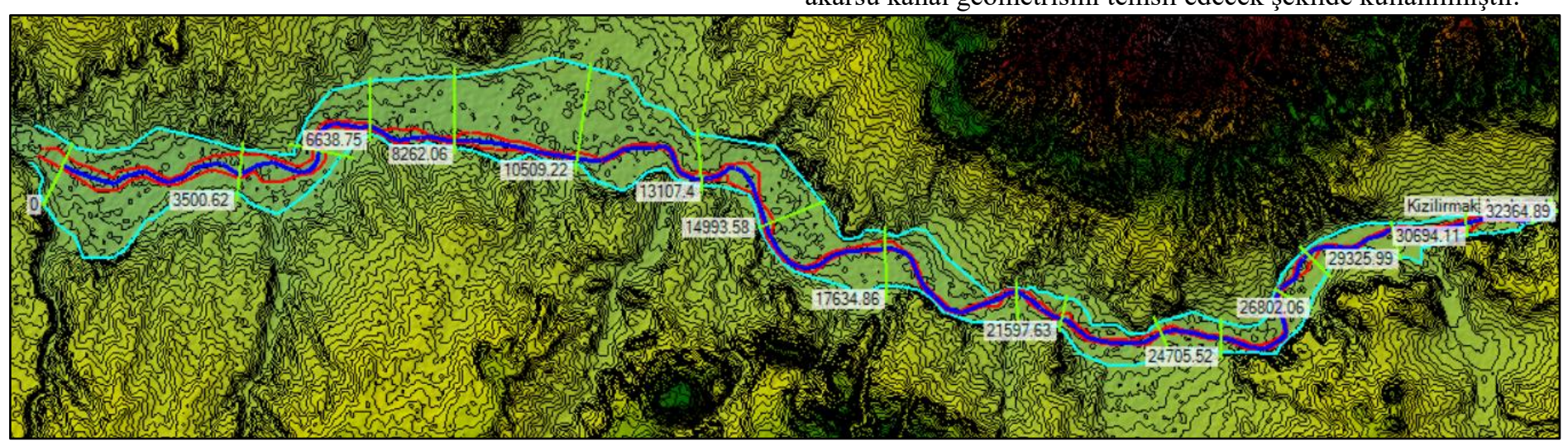

\section{Şekil 7. HEC-RAS Modeli, Anakanal, Taşkın Yatakları ve Enkesit Alınan Bölgeler}

\section{Hidrodinamik Model}

Chow'a (1959) göre nispeten sı ̆̆, kıyılarında su birikintileri bulunan, hafif eğim ve çukurlara sahip, tabanında yosun ve az miktarda çakıl bulunan doğal akarsu anakanallarda Manning denkleminde kullanılacak pürüzlülük katsayıları 0.040 - 0.055 arasında, yüksek otlara ya da ekilmiş alanlara sahip taşkın yataklarında ise $0.025-0.045$ arasında bulunmaktadır. Referans değerler göz önüne alınarak Manning pürüzlülük katsayısı enkesitlerde anakanal içerisinde kalan kısımda 0.05 ve taşkın yatağında ise 0.035 olarak belirlenmiştir.
HEC-RAS kararlı akım analizinde farklı istasyonlarda farklı debi değerleri ile çalışabilme olanağı sağlamaktadır. Bu sebeple kararlı akım simülasyonu, ölçüm noktalarında gözlemlenmiş debi değerlerine göre çalıştırılmıştır. Sınır koşulu olarak ölçülen mansap su kotu değeri 900,81m alınmıştır. Simülasyon debileri ve ölçüm noktalarına denk gelen istasyon kilometreleri, model ile hesaplanan maksimum ve ortalama su derinlikleri ve ölçüm değerleri ile aralarındaki fark oranları Tablo 2'de gösterilmektedir. Simülasyon sonucunda kesitlerde oluşan su derinlikleri Şekil 8'de ve su yüzü profili Şekil 9'da gösterilmektedir. 
Avrupa Bilim ve Teknoloji Dergisi

Tablo 2. Simülasyon Debileri ve Ölçüm Noktası İstasyon Kilometreleri

\begin{tabular}{l|c|c|c|c|c|c|c}
\hline & $\begin{array}{c}\text { Ölçüm } \\
\text { Noktası -1 }\end{array}$ & $\begin{array}{c}\text { Ölçüm } \\
\text { Noktası -2 }\end{array}$ & $\begin{array}{c}\text { Ölçüm } \\
\text { Noktası -3 }\end{array}$ & $\begin{array}{c}\text { Ölçüm } \\
\text { Noktası -4 }\end{array}$ & $\begin{array}{c}\text { Ölçüm } \\
\text { Noktası -5 }\end{array}$ & $\begin{array}{c}\text { Ölçüm } \\
\text { Noktası -6 }\end{array}$ & $\begin{array}{c}\text { Ölçüm } \\
\text { Noktası -7 }\end{array}$ \\
\hline İstasyon KM & 0.00 & 6638.75 & 20638.71 & 23588.59 & 24705.52 & 26802.03 & 32364.89 \\
\hline Simülasyon debisi (m) $/ \mathbf{s})$ & 25.00 & 66.40 & 68.10 & 6.75 & 7.94 & 10.90 & 7.45 \\
\hline Maks. Su derinliği (m) - Fark (\%) & $2.66-\% 20$ & $2.12-\% 39$ & $2.06-\% 60$ & $2.51-\% 12$ & $2.46-\% 3$ & $2.30-\% 48$ & $1.24-\% 7$ \\
\hline Ort. Su derinliği (m) - Fark (\%) & $1.93-\% 9$ & $1.43-\% 51$ & $0.87-\% 74$ & $1.24-\% 17$ & $1.34-\% 14$ & $1.98-\% 23$ & $1.02-\% 21$ \\
\hline
\end{tabular}

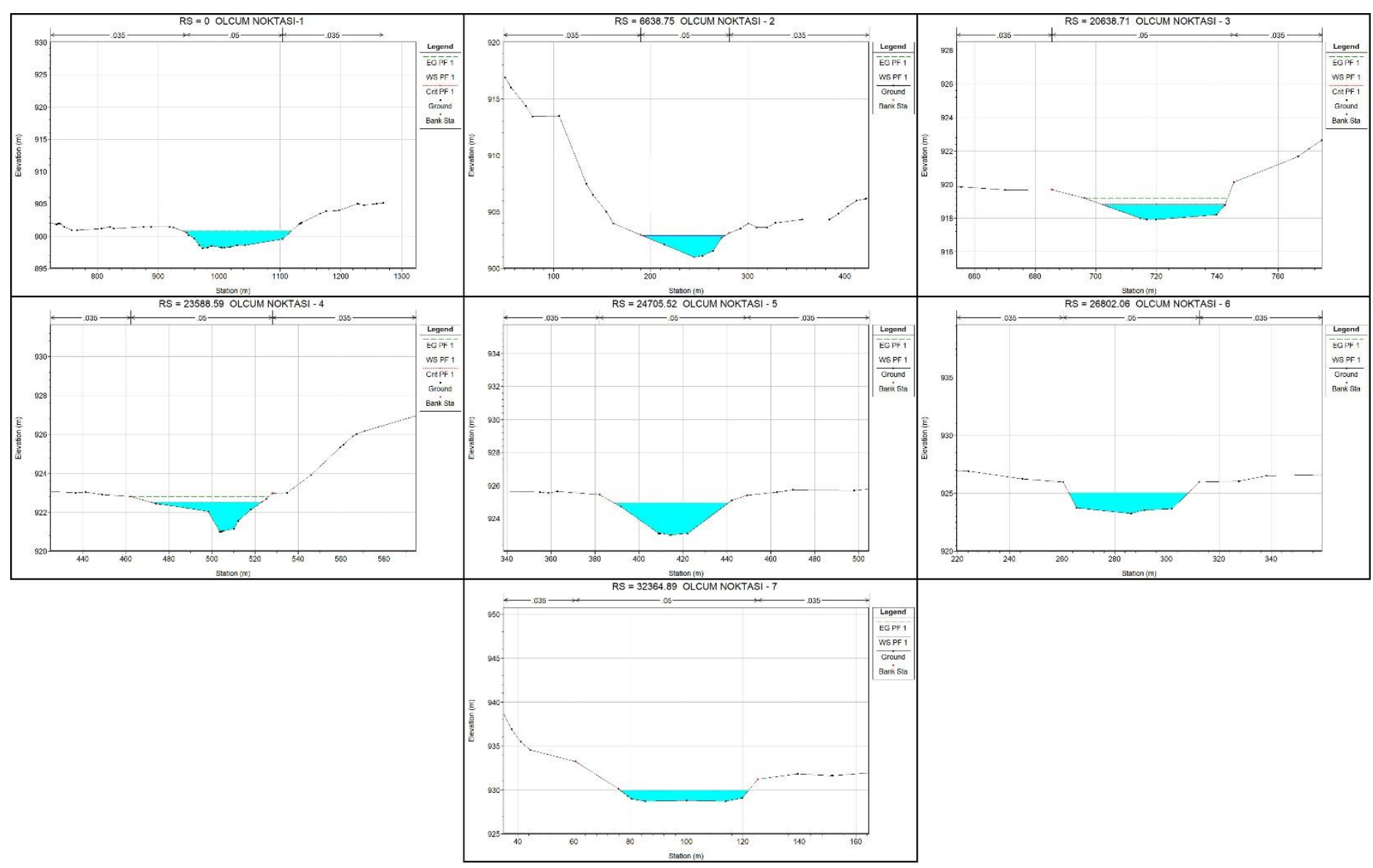

Sekil 8. HEC-RAS Modeli Kesitlerdeki Su Derinlikleri

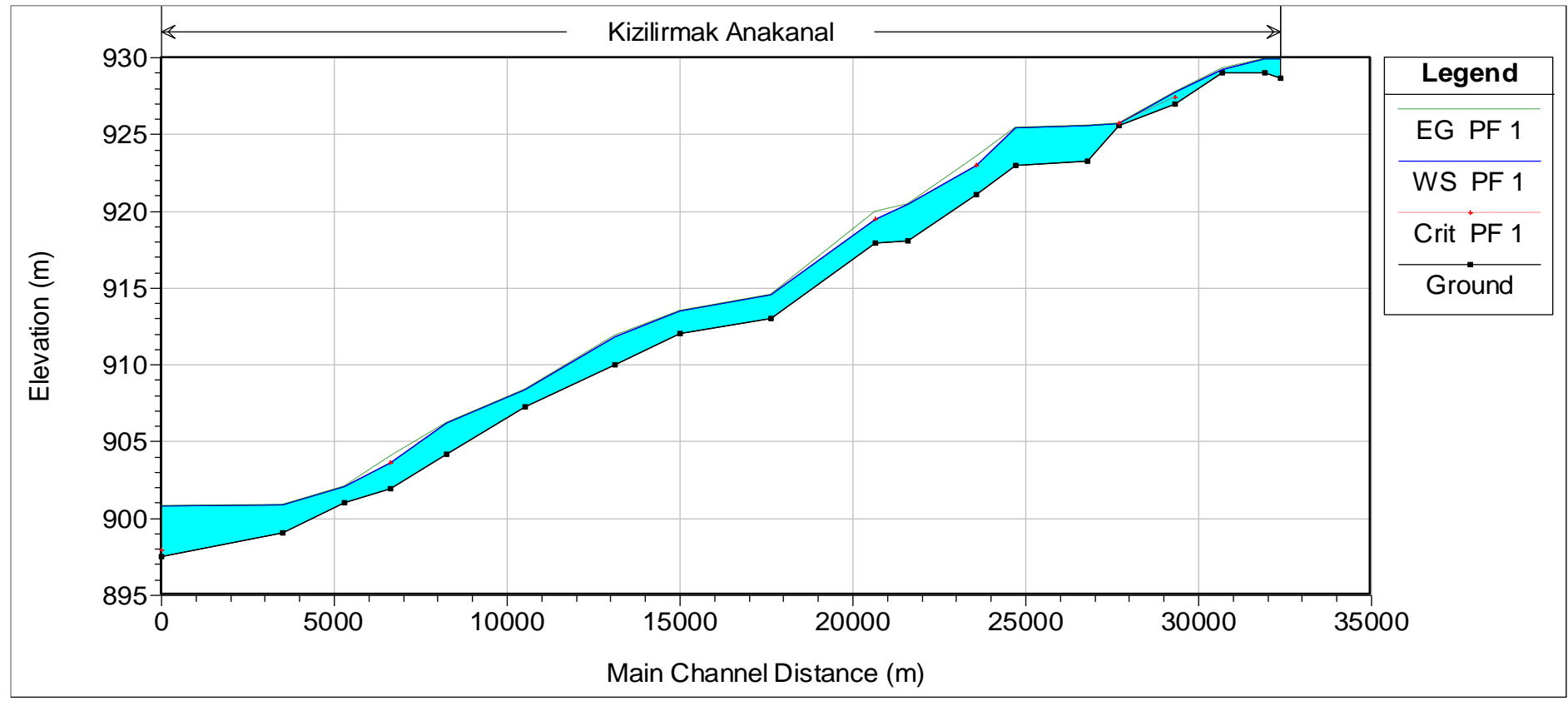

Şekil 9. HEC-RAS Modeli Su Yüzü Profili 


\section{Sonuç}

HEC-RAS ile oluşturulan kararlı akım modeli 1, 2 ve 3 nolu ölçüm noktalarından elde edilen nispeten diğer ölçümlerden yüksek olan debi değerleri ve $4,5,6$ ve 7 nolu noktalarda ölçülen düşük debi değerleri kullanılarak gerçekleştirilmiştir. Tablo 2'de hidrolik model ile hesaplanan ve ölçümlerden elde edilen maksimum su derinlikleri karşılaştırıldığında oluşan farkın en fazla $\% 60$ oran ile Ölçüm Noktas1-3'e ait veride gerçekleştiği Ölçüm Noktası-2'de ise \%39 oranında olduğu tespit edilmiştir. Ölçüm Noktaları 1, 4, 5 ve 7'de elde edilen maksimum su derinliklerindeki farkların ise \%3 ila $\% 20$ seviyesinde gerçekleştiği görülmektedir. Benzer şekilde, hesaplanan ve ölçülen ortalama su derinliklerindeki farklar ise Ölçüm Noktas1-3'de \%74, Ölçüm Noktas1-2'de \%51 oranında gerçekleşmiş, diğer ölçüm noktalarında ise \%9 ila \%23 oranında değişmektedir. Model ile ölçümler arasındaki farklılıklar, hidrolik modellemede kullanılan sayısal yüzey modelindeki yuvarlamalar, kabul edilen Manning katsayıları gibi parametrelerden kaynaklanmakta, hidrolik modellemede kullanılan yüzey modelinde ve hidrolik kabullerde hassasiyet arttırıldıkça modelin doğruluğu da buna paralel olarak artmaktadır.

\section{Teșekkür}

$\mathrm{Bu}$ çalışmanın saha araştırmaları kısmı, Nevşehir Hacı Bektaş Veli Üniversitesi, BAP Birimi bünyesinde, NEUBAP14F4 numaralı proje ile desteklenmiştir.

\section{Kaynakça}

Acarlar, M., Acarlar, S., Adır, M., Akpınar, A., Akarsu, B. ve diğ., (2002). 1:500.000 Ölçekli Türkiye jeoloji haritası Kayseri paftasi. Türkiye 1/500.000 Ölçekli Jeoloji Haritaları, No: 9, M. Şenel (Ed.), Maden Tetkik ve Arama Genel Müdürlüğü, Ankara.

Balas, L. \& Özhan, E. (2000). An implicit three dimensional numerical model to simulate transport processes in coastal water bodies. International Journal for Numerical Methods in Fluids, 34, 307-339. Retrieved from https://doi.org/10.1002/1097-0363(20001030)34:4\%3C307:: AID-FLD63\%3E3.0.CO;2-T

Balas, L. \& Cebe, K. (2021). Hydrodynamic modelling using HIDROTURK model. Turkish Journal of Water Science \& Management, 5 (1), 80-107. Retrieved from https://dergipark.org.tr/tr/pub/tjwsm/issue/59870/736066

Bilhan, Ö. (2017). Saha Çalışmaları ve Nümerik Modeller Kullanılarak Kızılırmak Havzasında Sediment Taşınımı ve Birikiminin Analizi. Nevşehir Hacı Bektaş T.C. Veli Üniversitesi Bilimsel Araştırma Projeleri Koordinasyon Birimi Projesi, NEÜBAP14F4 numaralı BAP, 56s, Nevşehir.

Brunner, G. W. (2021). HEC-RAS river analysis system hydraulic reference manual. Davis: US Army Corps of Engineers, Hydrologic Engineering Center. Retrieved from https://www.hec.usace.army.mil/software/hec-ras/ documentation/HEC-RAS_6.0_Reference_Manual.pdf

Brunner, G. W. \& CEIWR-HEC. (2021). HEC-RAS user's manual. Davis: US Army Corps of Engineers Hydrologic Engineering Center. Retrieved from https:// www.hec.usace.army.mil/software/hec-ras/documentation/ HEC-RAS\%205.0\%20Users\%20Manual.pdf
Cameron, T. \& Ackerman, P.E. (2012). HEC-GeoRAS, GIS Tools for Support of HEC-RAS using Arc-GIS 10, User's Manual, version 10. Davis: US Army Corps of Engineers Hydrologic Engineering Center. Retrieved from https:// www.hec.usace.army.mil/software/hec_georas/documentatio n/HEC-GeoRAS_43_Users_Manual.pdf

Cebe, K. \& Balas, L. (2016). Water quality modelling in Kaş Bay. Applied Mathematical Modelling, 40(3), 1887-1913. DOI: 10.1016/j.apm.2015.09.037

Chow, V. T. (1959). Open Channel Hydraulics. McGraw-Hill Book Company, NY.

Deltares. (2021). Delft3D-FLOW, Simulation of multidimensional hydrodynamic flows and transport phenomena, including sediments, User Manual, Hydro-Morphodynamics. Version 3.15. Delft.

DHI. (2017). A modelling system for rivers and channels. reference manual. Horsholm, Denmark. Retrieved from https://manuals.mikepoweredbydhi.help/2017/Water_Resour ces/Mike_11_ref.pdf

Doğu, A. \& Yıldız, O. (2019). Kırıkkale Çoruhözü Deresi'nde Bir Boyutlu Taşkın Modellemesi. K.Ü. Uluslararası Mühendislik Araştırma ve Geliştirme Dergisi. 11. cilt (2), 748-758.

ESRI. (2011). ArcGIS Desktop: Release 10.2. Redlands, CA: Environmental Systems Research Institute.

Maharjan, L.B. \& Shakya, N. M. (2016). Comparative Study of One Dimensional and Two Dimensional Steady Surface Flow Analysis. Journal of Advanced College of Engineering and Management, vol. 2.

NASA JPL (2013). NASA Shuttle Radar Topography Mission Global 1 arc second [Data set]. NASA EOSDIS Land Processes DAAC. Accessed 2021-11-19 from https://doi.org/10.5067/MEaSUREs/SRTM/SRTMGL1.003

Önal, S. (2009). Yapay Sinir Ağları Metodu ile Kızllırmak Nehri 'nin Akım Tahmini. Yüksek Lisans Tezi, Süleyman Demirel Üniversitesi, Isparta.

Rossman, L. A. (2006). Storm Water Management Model Quality Assurance Report: Dynamic Wave Flow Routing, (Report No. EPA/600/R-06/097). U.S.E.P.A., Office of Research and Development, National Risk Management Research Laboratory, Cincinnati, $\mathrm{OH}$.

Rossman, L. A. (2017). Stormwater Management Model Reference Manual, Volume-I Hydrology, (Report No. EPA/600/R-17/111). U.S. U.S.E.P.A., Office of Research and Development, Washington DC.

Tektaş, Y. \& Polat, N. (2021). HEC-RAS İle Taşkın Modelleme ve Sentinel-2 Uzaktan Algılama Görüntüsünden Taşkın Hasar Analizi: Diyarbakır İli Çakmak Deresi Çınar Bölgesi Örneği. Türkiye Uzaktan Algllama Dergisi, 3 (1), 28-35. DOI: $10.51489 /$ tuzal.924926

Wang, C. H. (2014). Application of HEC-RAS Model in Simulation of Water Surface Profile of River. Applied Mechanics and Materials, 641-642, 232-235. DOI:10.4028/www.scientific.net/amm.641-642.232

Yılmaz, C. (2005). Kizilırmak Deltasında Meydana Gelen Erozyonun Coğrafi Analizi. Türkiye Kuvaterner Sempozyuти, 2-5 Haziran 2005. İTÜ Avrasya Yer Bilimleri Enstitüsü, İstanbul.

Yılmaz, N., Bozkurt, H. \& Bayazit, Y. (2020). Akarsu Köprülerinin HEC-RAS Programı ile Hidrolik Analizi: Fidanlık Köprüsü Örneği. Bilecik Şeyh Edebali Üniversitesi Fen Bilimleri Dergisi, 7 (2), 896-910. DOI: 10.35193/bseufbd.715657. 